\title{
An Examination of Behavior Change Theories to Predict Behavioral Intentions of Organisms-in-Trade Hobbyists
}

\author{
Jessica Mayer \\ Duke Energy Corporation \\ Charlotte, North Carolina, United States \\ Erin Seekamp' \\ Department of Parks, Recreation and Tourism Management \\ North Carolina State University, Raleigh, United States \\ Jonathan Casper \\ Department of Parks, Recreation and Tourism Management \\ North Carolina State University, Raleigh, United States \\ Gary Blank \\ Department of Forestry and Environmental Resources \\ North Carolina State University, Raleigh, United States
}

\section{Abstract}

This study examined the effects of theoretical constructs from the theory of planned behavior (TPB) and value-belief-norm theory (VBN) on intentions to perform purchase and disposal behaviors that help prevent aquatic invasive species (AIS) spread by organisms-in-trade (OIT) hobbyists. More specifically, the goals of this study were to explore (1) the predictive ability of theoretical constructs on intention to perform desired behaviors and (2) differences in the strength of the constructs on future purchase and disposal behaviors. Regression analyses from survey research conducted at OIT events in the Great Lakes region $(\mathrm{n}=542)$ revealed that VBN constructs have direct, positive effects on likelihood of performing future purchase and disposal behaviors; one TPB construct (perceived behavioral control) also predicted likelihood of performing future disposal behaviors. Seemingly unrelated regression results demonstrate differing effects of theoretical constructs between purchase and disposal behaviors. Findings suggest tailoring messages to target specific behaviors.

1 Corresponding author: erin_seekamp@ncsu.edu. 
Keywords: aquatic invasive species, behavior change theories, organisms-intrade hobbyists, theory of planned behavior, value-belief-norm theory

\section{Introduction}

Non-native species have been deliberately introduced for centuries, as the wilderness was tamed, economic benefits realized, and mistakes made (Gozlan, 2008; Kareiva et al., 2007). However, shifts in desired environmental conditions to more "natural" flora and fauna (Hull, 2006) have occurred, particularly in freshwater ecosystems (Hermoso \& Clavero, 2013). Furthermore, environmental managers' concerns about deliberate (with some exceptions in the case of sport fisheries), accidental, and uninformed human behaviors that result in the establishment of non-native fish, reptile, amphibian, and plant species in aquatic ecosystems have increased as biological invasions continue to accelerate (e.g., Cucherousset \& Olden, 201 1; Vander Zanden \& Olden, 2008).

Aquatic invasive species (AIS) threaten natural ecosystems by outcompeting native species and creating significant biodiversity losses (Stiers et al., 2011), reducing recreational opportunities by altering sport fisheries and damaging infrastructure, boats, and water conveyance structures (ANS Task Force, 2012). Much attention has been directed toward the Great Lakes region, northeastern United States, where more than 180 non-native and invasive species have been identified (NOAA, 2015) and aggregated costs for mitigation and management are estimated at more than US\$100 million annually (Rosaen et al., 2012). Numerous pathways (i.e., vectors) exist for AIS to gain access to the Great Lakes, for example, commercial shipping, recreational boating, angling or bait fishing, aquaculture, commercial and home aquaria and water gardens, canals, and rivers (National Research Council, 2008).

Within the United States, participants in the organisms-in-trade (OIT) industry (namely aquarium hobbyists, water gardeners, and outdoor pond hobbyists; hereafter known as "OIT hobbyists") account for about one quarter of fish and amphibian releases and nearly three quarters of aquatic reptile releases (Fuller, 2003; Padilla \& Williams, 2004). The OIT pathway has resulted in the introduction of 21 documented species in the Great Lakes (Rothlisberger, 2009). Although the OIT industry accounts for only about six percent of AIS establishment in the Great Lakes region (Mills et al., 1994), management efforts are needed to control any and all human vectors of dispersal (Ruiz \& Carlton, 2003). Managers fear aquarium and water garden species (e.g., Misgurnus anguillicaudatus and Myriophyllum hertophyllum) will become established in the Great Lakes region (Rixon et al., 2005), and thus support eradication of nonnative species (Johnston \& Marks, 1997). However, management techniques, such 
as trade restrictions, have been considered ineffective, increasing the need for self-regulation (Selge et al., 2011). General awareness of environmental impacts caused by invasive species is relatively low (Bremner \& Park, 2007), suggesting that an educational outreach campaign may increase hobbyists' AIS awareness and lead to adoption of behaviors - specifically, aquatic species purchase and disposal behaviors - known to prevent the establishment and spread of AIS.

To date, limited knowledge exists concerning OIT hobbyists' awareness of AIS release consequences or concern about resulting environmental impacts. Previous research suggests that OIT hobbyists in four municipalities in the Great Lakes region (Duluth, Minnesota; Rochester, New York; Allentown, Pennsylvania; and Erie, Pennsylvania) are engaging in behaviors that lead to AIS establishment despite recognizing that it was not good for the environment (Green \& Armson, 2005). Therefore, the purpose of our study was to identify the best predictors of responsible OIT hobbyist behavior.

Constructs known to predict behavioral intentions were identified from previous studies of private-sphere environmentally responsible behaviors (i.e., "the purchase, use, and disposal of personal and household products that have environmental impact," as opposed to public-sphere behaviors, such as policy support, environmental citizenship, and environmental activism; Stern, 2000 , p. 409). In particular, the theory of planned behavior (TPB) and valuebelief-norm theory (VBN) have explained between 17 and 66 percent of the variance explaining intentions to engage in such private-sphere behaviors as wastepaper recycling and using high-efficiency light bulbs (Cheung et al., 1999; Chu \& Chiu, 2003; Harland et al., 1999). Furthermore, these theories have previously been applied in studies of other leisure behaviors related to the spread of AIS (e.g., boating; Cottrell, 2003) and to other actors in the OIT industry (e.g., horticulturalists; Burt et al., 2007). This study integrates constructs from these theories that have had previous direct relationships to behavioral intentions. As previous research suggests that individuals who partake in "green" purchasing behaviors also participate in "green" disposal behaviors (van Birgelen et al., 2008), we also examined whether the effect of the theoretical constructs differs when predicting the type of behavior OIT hobbyists intend to perform (i.e., purchase behaviors versus disposal behaviors). Ultimately, identifying the most important predictors of responsible OIT hobbyist behaviors can inform future educational outreach strategies aimed at increasing self-regulation. 


\section{Theoretical framework}

Integrating constructs from both $\mathrm{VBN}$ and $\mathrm{TPB}$ has been shown to increase the variance explained when predicting environmentally responsible behavior (Stern, 2000). In VBN, values held by an individual influence a set of beliefs (namely an ecological world view, awareness of consequences, and ascription of responsibility) that activate personal norms (Stern et al., 1999). Personal norms (also referred to as moral obligations) have been shown to directly influence responsible environmental behavioral intention in studies of energy conservation behaviors (Sahin, 2013) and personal car use (Nordlund \& Garvill, 2003). The TPB is composed of three constructs that predict responsible environmental behavioral intention, such as wastepaper recycling (Cheung et al., 1999) and household energy conservation (Midden \& Ritsema, 1983). Ajzen (1991) identified these constructs as attitudes (whether the individual views the behavior as negative or positive), subjective norm (alleged pressure from the individual's peers to perform the action), and perceived behavioral control (whether the individual feels that performing the action is within their ability).

In studies of private-sphere environmentally responsible behavior, such as household energy use, reducing meat consumption, and using unbleached paper (Abrahamse \& Steg, 2011; Harland et al., 1999), including personal norms with TPB constructs has substantially increased the explanatory power. We expand these studies by including all VBN constructs previously demonstrated to have a direct effect on private-sphere environmentally responsible behavioral intentions. Specifically, we postulate that awareness of AIS, concern for the environment, ascription of responsibility, internalized feelings to prevent the spread of AIS, perceived social pressures to engage in desired behaviors, and perceived control over engaging in future OIT behaviors will be positively related to intentions to perform responsible OIT purchase and disposal behaviors (Figure 1). 


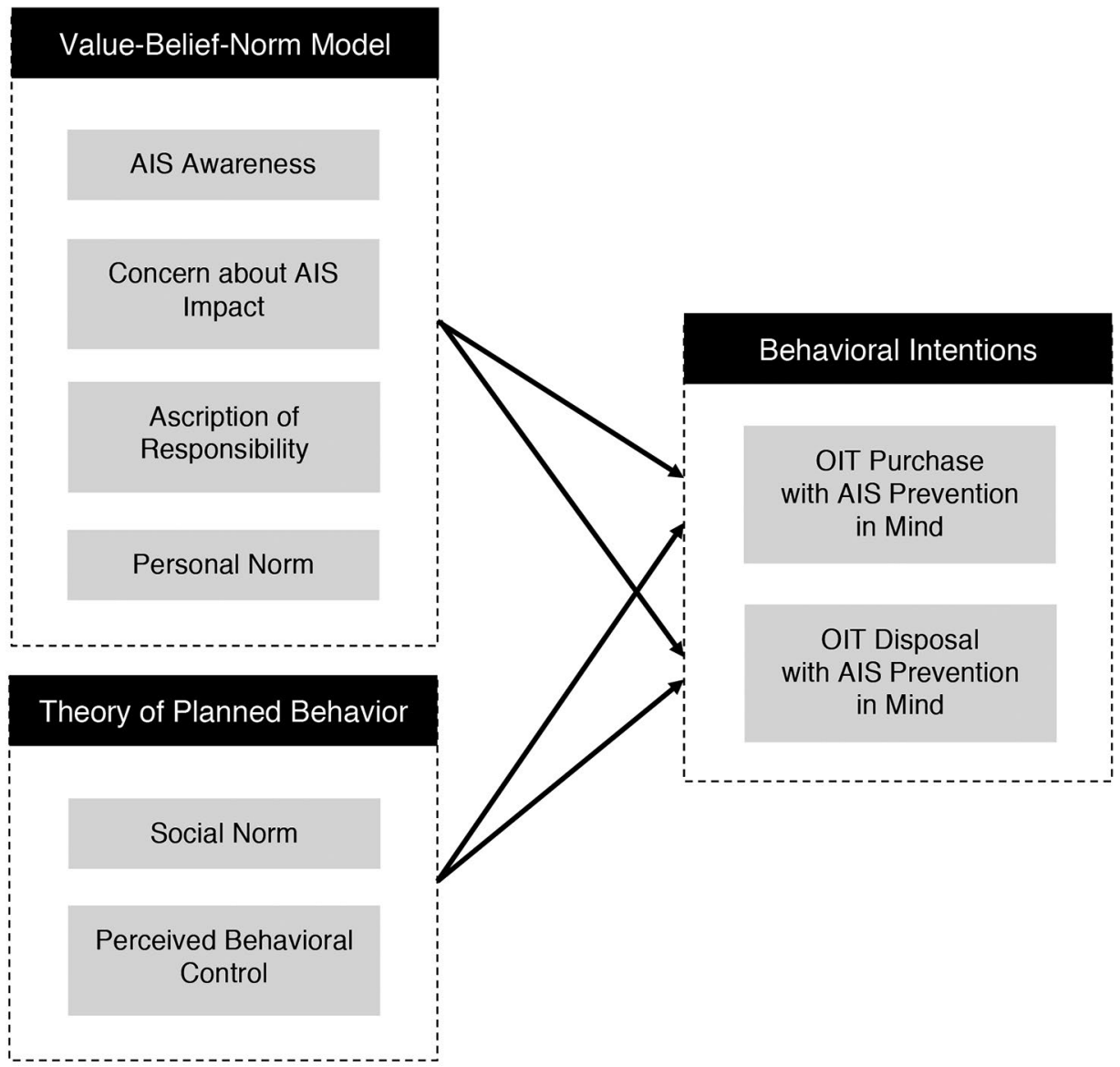

Figure 1. Integrated model to predict OIT hobbyists' intentions to make purchase and disposal behaviors with AIS prevention in mind

\section{Value-belief-norm model}

We were specifically interested in constructs that may directly influence behavioral intention; therefore, we included only behavior-specific belief constructs and did not include values in our model. For example, previous research has demonstrated that the new ecological paradigm has not had a direct effect on behavioral intention when other VBN constructs are included in a model (Abrahamse \& Steg, 2011; Steg et al., 2005). Additionally, as values (e.g., biospheric, altruistic, and egoistic) are postulated to predict new ecological paradigm beliefs in the VBN path to behavioral intentions, we did not include them in our integrated model.

Given that VBN is traditionally conceived as a path model (Stern, 2000; Stern et al., 1999), we explored not only the direct effects on behavioral intentions but also the paths between the behavior-specific beliefs and from 
these beliefs to personal norms. Our conceptualization of behavior-specific included environmental concern, awareness of consequences, and ascription of responsibility. Environmental concern is not typically a construct portrayed in VBN; however, it is oftentimes considered to be implicitly expressed in awareness of consequences and, thus, included in its measurement (Stern et al., 1993). Although Stern (2000, p. 409) explains that "environmental concerns are within awareness and may therefore be influential" in studies of public-sphere behaviors, he also states that "private-sphere behaviors are unlike publicsphere environmentalism in that they have direct environmental consequences" but that the impact of an individual's private-sphere behavior is small and, as such, "individual behaviors have environmentally significant impact only in the aggregate" (ibid., p. 410). Given the potential for direct, and potentially substantial, environmental consequences from AIS release, we postulated that environmental concerns would directly influence OIT hobbyists' intentions to perform environmentally responsible behaviors (particularly disposal behaviors, such as donating instead of releasing an unwanted fish, amphibian, or reptile species, or burning aquatic plants after weeding colonizing plants from ponds or water gardens).

Ecological problem awareness has been shown to have significant, direct effects on both personal norms and intention to engage in general environmentally responsible behaviors (Nordlund \& Garvill, 2002), conservation behaviors (Kaiser et al., 2005), and environmentally responsible boating behavior (Cottrell, 2003). However, current research has suggested that while the general public is aware of the term invasive species, they may not be aware of the effects that non-native species have on the environment (Sharp et al., 2011). Similar to problem awareness, environmental concern has been shown to have significant, direct effects on both personal norms (Nordlund \& Garvill, 2002) and behavioral intention (Mehmetoglu, 2010). Research on household energy conservation has demonstrated that environmental concern can also be mediated through ascription of responsibility to activate personal norms (Black et al., 1985). In a study of horticultural professionals, awareness of the invasive species problem was a significant predictor of participation in measures to prevent the spread of invasive species (Burt et al., 2007). Therefore, we propose the following hypotheses:

- H1.1: Awareness of AIS and environmental concern have direct, positive effects on ascription of responsibility to prevent the spread of AIS.

- H1.2: Awareness of AIS and environmental concern have direct, positive effects on personal norms.

- H1.3: Awareness of AIS and environmental concern have direct, positive effects on intentions to perform purchase and disposal behaviors with preventing AIS spread in mind. 
Like ecological problem awareness and environmental concern, ascription of responsibility is a belief construct in VBN. When an individual assumes some responsibility of the action, personal norms are activated and explain more of the variance in behavioral intention (Schwartz, 1968). Yet, not only has ascription of responsibility been shown to directly influence personal norms (Bamberg \& Schmidt, 2003; Kaiser et al., 2005), it has also had a positive, direct effect on intention to engage in recycling behaviors (Guagnano et al., 1995). Therefore, we propose the following hypotheses:

- H1.4: Ascription of responsibility to prevent the spread of AIS has a direct, positive effect on personal norms.

- H1.5: Ascription of responsibility has a direct, positive effect on intention to perform purchase and disposal behaviors with preventing AIS spread in mind.

Personal norms are indicative of the moral obligation one feels to perform specific behaviors (Schwartz, 1977). Personal norms, as theorized in VBN, have had positive, direct effects on behavioral intentions to perform conservation behaviors (e.g., environmental organization membership, recycling, energy conservation, purchasing eco-labeled products, alternative transportation; Kaiser et al., 2005; Nordlund \& Garvill, 2002). Therefore, we hypothesize that:

- H1.6: Personal norms have direct, positive effects on intention to perform purchase and disposal behaviors with preventing AIS spread in mind.

\section{The theory of planned behavior}

Research employing TPB constructs has predicted environmentally responsible behavioral intentions such as recycling (Cheung et al., 1999; Chu \& Chiu, 2003) and conservation behaviors (Kaiser et al., 2005). However, the effect of constructs (individually or collectively) on behavioral intention varies depending on the target behavior (Ajzen, 1991). Although the effect of attitudes on behavioral intentions is typically significant, the inclusion of personal norms in TPB studies has decreased the individual effect of attitudes but increased the variance explained by either model singularly (Harland et al., 1999). That is, a more robust set of psychological variables can "increase clarity," particularly by capturing moral considerations, in studies of environmentally responsible behavior (ibid., p. 2523). As the personal norm construct is an evaluative measure of moral obligation to perform the desired behavior (Corraliza \& Berenguer, 2000; Stern, 2000), we did not include attitudes in our integrated model. That is, we assumed that personal norm captures an individual's attitude toward performing the desired behavior. 
Subjective norms refer to the social pressure felt by the individual to perform the desired action (Ajzen, 1991). Subjective norms have been shown to have a significant effect on intention to engage in environmentally responsible behaviors, (e.g., recycling behaviors; Cheung et al., 1999). However, the unique influence of subjective norms on behavioral intention tends to be weaker than personal considerations (Ajzen, 1991) and the effect was also found to become insignificant when personal norms was added to the TPB models of four out of five distinct conservation behaviors (Harland et al., 1999). Given the potential for differences between perceived social pressures related to responsible OIT purchase and disposal behaviors, we included the subjective norm construct in our integrated model. As such, we postulate that:

- H2.1: Subjective norms have direct, positive effects on intention to perform purchase and disposal behaviors with the prevention of AIS spread in mind.

Perceived behavioral control (i.e., an individual's perception of having the ability to perform the desired behavior) has been shown to have a positive, direct effect on behavioral intention (Ajzen, 2002; Cheung et al., 1999; Harland et al., 1999). Research on responsible environmental behaviors has demonstrated that constraints such as time, money, and knowledge frequently impact perceptions of behavioral control (Steg \& Vlek, 2009). Effectively, the more control an individual feels over performing an action, the more likely they will be to engage in the action (Ajzen, 2002). For example, Harland et al.'s (1999) study demonstrated that the effect of perceived behavioral control on intentions to perform three of the five conservations behaviors was greater than other TPB predictors and personal norms. Therefore, we hypothesized that:

- H2.2: Perceived behavioral control has direct, positive effects on intention to perform purchase and disposal behaviors with the prevention of AIS spread in mind.

\section{Future purchase and disposal decisions}

To date, research on OIT behaviors has explored predictors of OIT purchasing intentions (e.g., horticultural professionals' willingness to engage in purchase behaviors that prevent the establishment of invasive species; Burt et al., 2007) and disposal intentions (e.g., aquarium hobbyists' involvement in practices known to increase the spread of AIS; Duggan, 2010) separately. However, little is known about whether the influence of the predictors differs between purchase and disposal behaviors. Research on more general "green" purchase (packaging) and disposal (recycling) behaviors has documented positive correlations between purchase and disposal decision-making (van Birgelen et al., 2008). Given the dearth of research comparing purchase and disposal decisions, van 
Birgelen et al.'s (2008) study suggests that the effect of theoretical constructs included in our integrated model may be the same for both future OIT purchase and disposal decisions. Therefore, we propose the following hypothesis:

- H3.0: The effect of theoretical constructs on intention to perform future purchase behaviors will not be significantly different than on intention to perform future disposal behaviors.

\section{Methods}

\section{Study design}

In this study, we used survey research methodology to collect self-reported data from OIT hobbyists. The survey instrument was informed by focus groups and key-informant interviews conducted in fall 2012 (Mayer \& Seekamp, 2013), previous OIT surveys (Green \& Armson, 2005), and consultation with AIS specialists. That is, project researchers conducted focus groups and keyinformant interviews with OIT hobbyists and reviewed other OIT survey instruments to determine questionnaire items, as well as had AIS specialists review the instrument. We administered a questionnaire through voluntary recruitment to a sample of self-identified OIT hobbyists at 16 OIT events in the Great Lakes region. Researchers attended one aquarium hobbyist and one water garden/outdoor pond owner event-auctions, trade shows, festivals, and expos - in each of the eight Great Lakes states (Illinois, Indiana, Michigan, Minnesota, New York, Ohio, Pennsylvania, and Wisconsin).

Events were strategically selected based on relevance to the OIT industry, date of event within study time frame (February-September 2013), and event coordinators' willingness to allow researchers to interact with attendees. Sampling days depended upon event length and ranged from one day (approximately 4 hours) to three days (approximately 27 hours). We obtained permission from event coordinators to set up a booth for survey administration. A poster advertising an iPad raffle (i.e., incentive for participation) was hung at the booth to make attendees aware of the study and encourage participation.

Researchers stayed at the booths and did not directly approach event participants; however, event coordinators were asked to make a brief announcement to attendees about the study and provide the location of the booth. Adults (over the age of 18) who approached the booth and self-identified as an OIT hobbyist were asked to participate in the study. Respondents had the option of completing the survey on paper, on an iPad, or via email. We used a modified version of Dillman's (2007) tailored design method for the email version of the 
survey. A Kruskal Wallis test indicated that no differences existed between survey types in regard to age $\left(\chi^{2}=1.45, p=.49\right)$ or hobbyist classification $\left(\chi^{2}=4.81, p=.09\right)$.

\section{Respondents}

A total of 654 qualified individuals were asked to participate in the study and 542 surveys were completed (111 iPad surveys, 381 paper surveys, 50 email surveys), yielding an $83 \%$ response rate. After removing surveys (a) completed by individuals who were not current hobbyists but intended to be in the next three years and (b) with more than $50 \%$ of the theoretical questionnaire items missing responses, 481 valid surveys were retained for analysis. Remaining missing data were replaced with the series median (Acuña \& Rodriguez, 2004). Missing values ranged between zero and 33 cases for each independent and dependent variable, with an average of five missing cases per variable.

Within the valid data set, $48 \%$ of participants identified as primarily aquarium hobbyists, $22 \%$ identified as primarily water garden or outdoor pond hobbyists, and $30 \%$ owned both an aquarium and outdoor pond or water garden (Table 1). The majority of respondents were male $(61 \%)$ and the median age group was 50-59 years of age. More than half the respondents had a bachelor's degree or higher $(51 \%)$ and $57 \%$ of respondents had an annual household income greater than $\$ 60,000$ per year.

Table 1. Demographic results of participants

\begin{tabular}{|c|c|c|}
\hline & Frequency & Percent \\
\hline \multicolumn{3}{|l|}{ Hobbyist type } \\
\hline Aquarium hobbyist & 233 & 48 \\
\hline Outdoor pond/water garden owner & 103 & 22 \\
\hline Both aquarium and outdoor pond/water garden owner & 145 & 30 \\
\hline \multicolumn{3}{|l|}{ Gender } \\
\hline Male & 290 & 61 \\
\hline Female & 183 & 39 \\
\hline \multicolumn{3}{|l|}{ Age } \\
\hline $18-29$ & 54 & 12 \\
\hline 30-39 & 60 & 13 \\
\hline $40-49$ & 99 & 21 \\
\hline $50-59$ & 157 & 33 \\
\hline 60 and older & 101 & 21 \\
\hline
\end{tabular}




\begin{tabular}{|l|r|r|}
\hline \multicolumn{2}{|l|}{ Frequency } & Percent \\
\hline Education level & 2 & $<1$ \\
\hline Less than high school & 54 & 12 \\
\hline $\begin{array}{l}\text { High school diploma or General Education Development high school } \\
\text { equivalency credential }\end{array}$ & 113 & 24 \\
\hline College & 60 & 13 \\
\hline 2-year degree (associate) & 137 & 29 \\
\hline 4-year degree (bachelor) & 67 & 14 \\
\hline Master's degree & 12 & 3 \\
\hline Professional degree & 26 & 6 \\
\hline Doctoral degree & & \\
\hline Annual household income & 30 & 7 \\
\hline Under \$20,000 & 51 & 11 \\
\hline \$20,000-\$39,999 & 113 & 25 \\
\hline$\$ 40,000-\$ 59,999$ & 74 & 16 \\
\hline$\$ 60,000-\$ 79,999$ & 71 & 16 \\
\hline$\$ 80,000-\$ 99,999$ & 111 & 25 \\
\hline Over \$100,000 & & \\
\hline
\end{tabular}

\section{Sampling bias}

Individuals who approached the research booth and qualified for the study but declined to participate were asked to answer a series of six questions to determine if nonrespondents were statistically different from respondents. The questions included measures of age, hobbyist type, familiarity with AIS, level of concern with AIS spread, and past behaviors made with AIS prevention in mind. Twenty-one hobbyists answered the nonresponse bias check questions and no significant differences between respondents and nonrespondents were found.

\section{Survey questionnaire}

Questionnaire items were measured on a five-point Likert-type scale that ranged from 1 (strongly disagree) to 5 (strongly agree) (unless otherwise noted). When applicable, items were reverse coded so higher-scale scores reflected higher associations with corresponding constructs. Based on the theoretical framework, a six-factor solution (i.e., AIS awareness, concern about AIS impacts, ascription of responsibility, personal norms, subjective norms, and perceived behavioral control) was specified during a principal component analysis with Varimax rotation. However, after removing items loading less than 0.60 (see Appendix A), a five-factor solution emerged (Table 2). Based on these components, we created a mean rating of each construct. 
Table 2. Mean and standard deviation of theoretical constructs and factor loadings after Varimax rotation

\begin{tabular}{|c|c|c|c|c|c|c|c|}
\hline Question & Mean & SD & & & Factor & & \\
\hline & & & 1 & 2 & 3 & 4 & 5 \\
\hline Personal norm & 4.22 & 0.62 & & & & & \\
\hline $\begin{array}{l}\text { I am willing to put extra effort into } \\
\text { preventing the spread of AIS. }\end{array}$ & & & 0.842 & & & & \\
\hline $\begin{array}{l}\text { I feel a strong, personal obligation to } \\
\text { prevent the spread of AIS. }\end{array}$ & & & 0.807 & & & & \\
\hline $\begin{array}{l}\text { I feel that I should perform behaviors that } \\
\text { prevent the spread of AlS to protect local } \\
\text { waterways and environments. }\end{array}$ & & & 0.787 & & & & \\
\hline Awareness and concern & 4.27 & 0.62 & & & & & \\
\hline I am aware of the effects of AIS. & & & & 0.797 & & & \\
\hline $\begin{array}{l}\text { AlS have a negative impact on native } \\
\text { species in my region. }\end{array}$ & & & & 0.703 & & & \\
\hline $\begin{array}{l}\text { I have a general concern for the } \\
\text { environment. }\end{array}$ & & & & 0.753 & & & \\
\hline Perceived behavioral control & 3.82 & 0.78 & & & & & \\
\hline $\begin{array}{l}\text { I do not have enough time to perform } \\
\text { behaviors that prevent the spread of AIS. }\end{array}$ & & & & & 0.731 & & \\
\hline $\begin{array}{l}\text { I do not have enough information to } \\
\text { know how to prevent the spread of AIS. }\end{array}$ & & & & & 0.764 & & \\
\hline $\begin{array}{l}\text { Performing behaviors that prevent the } \\
\text { spread of AIS costs too much money. }\end{array}$ & & & & & 0.771 & & \\
\hline Ascription of responsibility & 4.07 & 0.75 & & & & & \\
\hline $\begin{array}{l}\text { Hobbyists like me can reduce the spread } \\
\text { of AlS. }\end{array}$ & & & & & & 0.738 & \\
\hline $\begin{array}{l}\text { It is possible for me to prevent the spread } \\
\text { of AlS. }\end{array}$ & & & & & & 0.866 & \\
\hline Subjective norm & 4.05 & 0.69 & & & & & \\
\hline $\begin{array}{l}\text { As part of the aquarium, outdoor } \\
\text { pond, or water garden community, it is } \\
\text { expected of me to perform behaviors } \\
\text { that prevent the spread of AIS. }\end{array}$ & & & & & & & 0.844 \\
\hline $\begin{array}{l}\text { Most people who are important to me } \\
\text { would want me to perform behaviors that } \\
\text { prevent the spread of AIS. }\end{array}$ & & & & & & & 0.686 \\
\hline Eigenvalue & & & 4.90 & 1.32 & 1.20 & 1.00 & .82 \\
\hline Explained variance & & & 37.5 & 10.2 & 9.2 & 7.7 & 6.3 \\
\hline Cronbach's alpha & & & .88 & .69 & .69 & .64 & .60 \\
\hline
\end{tabular}

Note. Only factor loadings greater than 0.60 are shown. All perceived behavioral control questionnaire items were reverse coded. 


\section{Value-belief-norm variables}

The principal component analysis merged awareness and concern into one component, creating a three-item factor, with two questionnaire items measuring awareness ("I am aware of the effects of AIS" and "AIS have a negative impact on native species in my region") and one questionnaire item measuring concern ("I have a general concern for the environment"). Overall, respondents reported a high level of awareness and concern $(\alpha=.69, \bar{X}=4.3, \mathrm{SD}=.62)$.

Two items were extracted that reflected the construct ascription of responsibility ("Hobbyists like me can reduce the spread of AIS" and "It is possible for me to prevent the spread of AIS"). The reliability of the scale was satisfactory ( $\alpha=.64$, $\overline{\mathrm{X}}=4.07, \mathrm{SD}=.75)$.

Personal norm included measures of respondents' moral obligation to perform behaviors to prevent the spread of AIS ("I am willing to put extra effort into preventing the spread of AIS," "I feel a strong, personal obligation to prevent the spread of AIS," and "I feel that I should perform behaviors that prevent the spread of AIS to protect local waterways and environments"). Respondents tended to agree that they held a high personal norm for AIS prevention $(\alpha=.88$, $\overline{\mathrm{X}}=4.2, \mathrm{SD}=.62$ ).

\section{Theory of planned behavior variables}

Two questionnaire items measuring subjective norm were extracted during the principal component analysis ("Most people who are important to me would want me to perform behaviors that prevent the spread of AIS" and "As part of the aquarium, outdoor pond, or water garden community, it is expected of me to perform behaviors that prevent the spread of AIS"). On average, respondents reported strong agreement in regard to subjective norm $(\alpha=.60, \bar{X}=4.0$, $\mathrm{SD}=.69)$.

Perceived behavioral control referred to the extent that respondents could participate in behaviors known to prevent the spread of AIS ("I do not have enough time to perform behaviors that prevent the spread of AIS," "I do not have enough information to know how to prevent the spread of AIS," and "Performing behaviors that prevent the spread of AIS costs too much money"). Items were reverse coded to associate higher agreement with higher perceived control. Overall, respondents tended to perceive that engaging in behaviors known to prevent the spread of AIS was in their control $(\alpha=.69, \bar{X}=3.8$, $\mathrm{SD}=.78)$. 


\section{Dependent variables}

Global measures of behavioral intention were used, based on the variability of hobbyist type and intended behavior. For example, a questionnaire item related to freezing aquatic plants before disposal is hobbyist-specific (i.e., hobbyists who only own aquatic fauna would not intend to engage in this behavior in the future). Responses were measured on a five-point Likert-type scale from 1 (not at all likely) to 5 (extremely likely). Specifically, respondents were asked "In the future, how likely are you to make decisions about purchases with preventing the spread of AIS in mind." Respondents tended to agree that they would be very likely to engage in the behavior in the future $(\bar{X}=3.7, S D=1.1)$. Respondents were also asked about future disposal decisions ("In the future, how likely are you to make decisions about disposal with preventing the spread of AIS in mind"). Again, respondents tended to agree that they would be very likely to engage in this behavior in the future $(\overline{\mathrm{X}}=4.2, \mathrm{SD}=0.93)$.

\section{Analysis}

We used linear regression to determine the relationship between variables in the proposed model. Additionally, we used Zellner's (1962) seemingly unrelated regression (SUR) technique to conduct a joint estimation of two regression equations (each having the same independent variables with different dependent variables). The SUR technique was performed to test whether the unique effects of the theoretical constructs differed for future purchase decisions and future disposal decisions with preventing the spread of AIS in mind. This estimation technique allows for correlation among residuals (i.e., the interrelated nature of purchase and disposal behaviors), using the Breusch-Pagan test to determine whether the residuals from the two equations are independent.

\section{Results}

A series of linear regression analyses were conducted to test the first eight hypotheses (H1.1-H2.2). First, we present results of the relationship between VBN variables, specifically hypotheses H1.1, H1.2 and H1.4. We then present the results of the integrated model, including the relationship between personal norms (from VBN) and perceived behavioral control and subjective norms (from $\mathrm{TPB}$ ) on future purchase and future disposal decisions (i.e., H1.6, H2.1, H2.2). Additionally, we present a significant improvement in the model with the addition of awareness and concern and ascription of responsibility ( $\mathrm{Hl}$.3, H1.5). Finally, we present results from the SUR analysis, comparing the net effect of the theoretical constructs on each of the dependent variables (H3.0). 


\section{Relationships between VBN variables}

Although the model was significant, the awareness and concern composite variable explained only 8 percent of the variance in ascription of responsibility $\left(R=.28, R^{2}=.08, \mathrm{~F}(1,479)=40.62, p<.001\right)$. However, awareness and concern had a greater positive, significant effect on personal norm $\left(R=.48, R^{2}=.28\right.$, $\mathrm{F}(1,479)=142.78, p<.001)($ Table 3$)$.

Ascription of responsibility explained a moderate amount of variance in personal norm $\left(R=.44, R^{2}=.19, \mathrm{~F}(1,479)=114.89, p<.001\right)$; however, the inclusion of awareness and concern increased the variance explained in personal norm $\left(R=.58, R^{2}=.33, \mathrm{~F}(2,478)=118.31, p<.001\right)$ (Table 4). Respondents with high awareness and concern $(\beta=.33, \mathrm{t}=8.52, p<.001)$ and high ascription of responsibility $(\beta=.39, \mathrm{t}=9.92, p<.001)$ reported higher personal norms. This finding justified our inclusion of ascription of responsibility and awareness and concern in the final model (i.e., testing direct effects of ascription of responsibility and awareness and concern on future purchase and future disposal behaviors).

Table 3. Regression results of awareness and concern with ascription of responsibility and awareness and concern with personal norm

\begin{tabular}{|c|c|c|c|c|c|c|c|c|c|c|}
\hline & \multicolumn{9}{|c|}{ AWCO $\rightarrow$ AR } & \multicolumn{5}{c|}{ AWCO $\rightarrow \mathrm{PN}$} \\
\hline & $\boldsymbol{\beta}$ & $\mathbf{t}$ & $\boldsymbol{R}$ & $\boldsymbol{R}^{2}$ & $\mathbf{F}$ & $\boldsymbol{\beta}$ & $\mathbf{t}$ & $\boldsymbol{R}$ & $\boldsymbol{R}^{2}$ & $\mathbf{F}$ \\
\hline & & & .28 & .08 & $40.62^{\star \star \star}$ & & & .48 & .23 & $142.78^{\star \star \star}$ \\
\hline AWCO & .28 & $6.37^{\star \star \star}$ & & & & .48 & $11.95^{\star \star \star}$ & & & \\
\hline
\end{tabular}

Note. $\mathrm{AWCO}=$ awareness and concern, $\mathrm{AR}=$ ascription of responsibility, $\mathrm{PN}=$ personal norm.

${ }^{\star \star *} p<.001$.

Table 4. Regression results of ascription of responsibility and awareness and concern on personal norm

\begin{tabular}{|l|c|c|c|c|c|c|c|c|c|c|}
\hline & \multicolumn{5}{|c|}{ AR $\rightarrow \mathrm{PN}$} & \multicolumn{5}{c|}{ AR, AWCO $\rightarrow \mathrm{PN}$} \\
\hline & $\boldsymbol{\beta}$ & $\mathbf{t}$ & $\boldsymbol{R}$ & $\boldsymbol{R}^{\mathbf{2}}$ & $\mathbf{F}$ & $\boldsymbol{\beta}$ & $\mathbf{t}$ & $\boldsymbol{R}$ & $\boldsymbol{R}^{\mathbf{2}}$ & $\mathbf{F}$ \\
\hline & & & .44 & .19 & $114.89^{\star \star \star}$ & & & .58 & .33 & $118.31^{\star \star \star}$ \\
\hline AR & .44 & $10.72^{\star \star \star}$ & & & & .33 & $8.52^{\star \star \star}$ & & & \\
\hline AWCO & & & & & & .39 & $9.92^{\star \star \star}$ & & & \\
\hline
\end{tabular}

Note. $\mathrm{AWCO}=$ awareness and concern, $\mathrm{AR}=$ ascription of responsibility, $\mathrm{PN}=$ personal norm.

${ }^{\star \star \star} p<.001$. 


\section{Relationships between VBN variables, TPB variables, and future purchase and future disposal behaviors}

We first explored the relationship between personal norm, subjective norm, and perceived behavioral control. Next, we added the theoretical constructs from VBN (i.e., awareness and concern, and ascription of responsibility) that had a positive, direct effect on behavioral intention. In the first model that tested the effect of personal norm, subjective norm, and perceived behavioral control, personal norm was the only significant construct in the model when predicting behavioral intention of future purchase decisions $\left(R=.46, R^{2}=.21\right.$, $\mathrm{F}(3,477)=41.41, p<.001$; Table 5). Specifically, the first model illustrated that the higher the personal norm reported by respondents, the more likely they reported making future purchase decisions with preventing the spread of AIS in mind $(\beta=.43, \mathrm{t}=8.16, p<.001)$. When awareness and concern and ascription of responsibility were entered into the regression model, $24 \%$ of the variance in intention to make future purchase decisions to prevent the spread of AIS was explained $\left(R=.49, R^{2}=.24, \mathrm{~F}(5,475)=30.10, p<.001\right)$. All VBN composite variables had a significant, positive effect on intention to make purchase decisions with AIS prevention in mind (personal norm, $\beta=.34$, $\mathrm{t}=6.18, p<.001$; ascription of responsibility, $\beta=.11, \mathrm{t}=2.24, p<.05$; awareness of AIS and environmental concern, $\beta=.18, \mathrm{t}=3.93, p<.001$ ).

Variables from the TPB and personal norm were significant when predicting behavioral intention of future disposal decisions $\left(R=.52, R^{2}=.27, \mathrm{~F}(3,477)\right.$ $=57.66, p<.001$; Table 6$)$. Higher personal norms $(\beta=.34, \mathrm{t}=6.68, p<.001)$, perceived behavioral control $(\beta=.20, \mathrm{t}=4.47, p<.001)$, and subjective norm $(\beta=.09, \mathrm{t}=2.03, p<.05)$ had significant, positive effects on making future purchase decisions with preventing the spread of AIS in mind. When awareness and concern and ascription of responsibility were entered into the model $\left(R=.56, R^{2}=.31, \mathrm{~F}(5,475)=43.31, p<.001\right)$, the effect of subjective norms disappeared. Respondents with higher perceived behavioral control $(\beta=.14$, $\mathrm{t}=3.23, p<.001)$, higher personal norm $(\beta=.23, \mathrm{t}=4.39, p<.001)$, higher ascription of responsibility $(\beta=.20, \mathrm{t}=4.38, p<.001)$, and higher awareness and concern $(\beta=.15, \mathrm{t}=3.45, p<.001)$ were related to increased likelihood of performing future disposal decisions with preventing the spread of AIS in mind. 
Table 5. Regression results of TPB and VBN variables on likelihood of making future purchase decisions with preventing the spread of AIS in mind

\begin{tabular}{|l|r|c|c|c|c|c|c|c|c|c|}
\hline & \multicolumn{5}{|c|}{$\begin{array}{c}\text { PN, PBC, SN } \rightarrow \\
\text { Future purchase }\end{array}$} & \multicolumn{5}{c|}{ Future purchase } \\
\hline & $\boldsymbol{\beta}$ & $\mathbf{t}$ & $\boldsymbol{R}$ & $\boldsymbol{R}^{2}$ & $\mathbf{F}$ & $\boldsymbol{\beta}$ & $\mathbf{t}$ & $\boldsymbol{R}$ & $\boldsymbol{R}^{\mathbf{2}}$ & $\mathbf{F}$ \\
\hline & & & .46 & .21 & $41.41^{\star \star \star}$ & & & .49 & .24 & $30.10^{\star \star \star}$ \\
\hline PBC & -.03 & -.67 & & & & -.07 & -1.60 & & & \\
\hline SN & .07 & 1.45 & & & & .03 & .64 & & & \\
\hline PN & .43 & $8.16^{\star \star \star}$ & & & & .34 & $6.18^{\star \star \star}$ & & & \\
\hline AR & & & & & & .11 & $2.24^{\star}$ & & & \\
\hline AWCO & & & & & & .18 & $3.93^{\star \star *}$ & & & \\
\hline
\end{tabular}

Note. $\mathrm{AWCO}=$ awareness and concern, $\mathrm{AR}=$ ascription of responsibility, $\mathrm{PBC}=$ perceived behavioral control, $\mathrm{PN}=$ personal norm, $\mathrm{SN}=$ subjective norm.

${ }^{*} p<.05 .{ }^{* * *} p<.001$.

Table 6. Regression results of TPB and VBN variables on likelihood of making future disposal decisions with preventing the spread of AIS in mind

\begin{tabular}{|l|c|c|c|c|c|c|c|c|c|c|}
\hline & \multicolumn{5}{|c|}{ PN, PBC, SN $\rightarrow$} & \multicolumn{5}{c|}{ PN, PBC, SN, AR, AWCO $\rightarrow$} \\
\hline & $\boldsymbol{B}$ & $\mathbf{t}$ & $\boldsymbol{R}$ & $\boldsymbol{R}^{2}$ & $\mathbf{F}$ & $\boldsymbol{\beta}$ & $\mathbf{t}$ & $\boldsymbol{R}$ & $\boldsymbol{R}^{2}$ & $\mathbf{F}$ \\
\hline & & & .52 & .27 & $57.66^{\star \star \star}$ & & & .56 & .31 & $43.31^{\star \star \star}$ \\
\hline PBC & .20 & $4.47^{\star \star \star}$ & & & & .14 & $3.23^{\star \star \star}$ & & & \\
\hline SN & .09 & $2.03^{\star}$ & & & & .05 & 1.02 & & & \\
\hline PN & .34 & $6.68^{\star \star}$ & & & & .23 & $4.39^{\star \star \star}$ & & & \\
\hline AR & & & & & & .20 & $4.38^{\star \star \star}$ & & & \\
\hline AWCO & & & & & & .15 & $3.45^{\star \star \star}$ & & & \\
\hline
\end{tabular}

Note. $\mathrm{AWCO}=$ awareness and concern, $\mathrm{AR}=$ ascription of responsibility, $\mathrm{PBC}=$ perceived behavioral control, $\mathrm{PN}=$ personal norm, $\mathrm{SN}=$ subjective norm.

${ }^{*} p<.05 .{ }^{* * *} p<.001$.

\section{Seemingly unrelated regression results}

The dependent variables were found to be interdependent. The bivariate correlation between purchase intentions and disposal intentions was .50 $(p<.001)$. Moreover, the Breusch-Pagan test was significant $\left(\chi^{2}(1 \mathrm{df})=55.74\right.$, $p<.001)$, indicating that the use of the SUR technique was valid. 
With the exception of subjective norm, all variables were significantly different in regard to their effect on likelihood of making future purchase and future disposal decisions with preventing the spread of AIS in mind (Table 7). Personal norm $\left(\chi^{2}=44.37, p<.001\right)$ and ascription of responsibility $\left(\chi^{2}=27.64, p<.001\right)$ had significantly larger effects on likelihood of making future purchase decisions with preventing the spread of AIS in mind, while perceived behavioral control $\left(\chi^{2}=18.62, p<.001\right)$ and awareness and concern $\left(\chi^{2}=12.96, p<.01\right)$ had significantly larger effects on likelihood of making future disposal decisions with preventing the spread of AIS in mind.

Table 7. Likelihood of making future purchase and disposal behaviors with preventing the spread of AIS in mind by TPB and VBN variablesSUR results

\begin{tabular}{|l|c|c|c|c|c|}
\hline \multirow{2}{*}{ Independent variable } & \multicolumn{2}{|c|}{$\begin{array}{c}\text { Future purchase } \\
\text { decisions }\end{array}$} & \multicolumn{2}{c|}{$\begin{array}{c}\text { Future disposal } \\
\text { decisions }\end{array}$} & \\
\cline { 2 - 6 } & Coefficient & SE & Coefficient & SE & $\begin{array}{c}\mathbf{X}^{2} \text { test of equation } \\
\text { differences (1df) }\end{array}$ \\
\hline Perceived behavioral control & -.11 & .07 & $.17^{\star \star}$ & .05 & $18.62^{\star \star \star}$ \\
\hline Subjective norm & .05 & .08 & .06 & .06 & .13 \\
\hline Personal norm & $.62^{\star \star \star}$ & .10 & $.35^{\star \star \star}$ & .08 & $44.37^{\star \star \star}$ \\
\hline Ascription of responsibility & $.27^{\star \star \star}$ & .07 & $.24^{\star \star \star}$ & .05 & $27.64^{\star \star \star}$ \\
\hline Awareness and concern & $.19^{\star}$ & .08 & $.23^{\star \star}$ & .07 & $12.96^{\star \star}$ \\
\hline$R^{2}$ & .24 & & .31 & & \\
\hline
\end{tabular}

${ }^{\star} p<.05 .{ }^{\star \star} p<.01 .{ }^{* \star \star} p<.001$.

\section{Discussion}

This study provides evidence that OIT hobbyists' intentions to make future purchase and disposal decisions with AIS spread prevention in mind are partially explained by variables from the TPB and VBN. Additionally, we found direct effects on behavioral intentions from VBN variables, which are traditionally mediated through other variables to predict behavioral intention. Finally, we documented that these psychological variables had different effects on both purchase and disposal intentions.

Theoretically, this study provides evidence for VBN constructs as better explanatory predictors of behavioral intention than TPB constructs, suggesting that internalized feelings have a more powerful influence than external or knowledge-based resources and social pressures when predicting privatesphere, environmentally responsible behavioral intentions. As shorter campaign 
messages are more powerful in reaching leisure audiences (Ham, 2013) and finite resources may limit campaign material development, it is important to understand these differing effects on OIT purchase and disposal behaviors, particularly in outreach campaign development. Thus, this study identifies specific theoretical constructs that should drive educational outreach messages to enhance adoption of behaviors that may prevent the spread of AIS.

In line with our first hypothesis (H1.1), awareness and concern (as a single construct) had a direct, positive effect on ascription of responsibility. Additionally, awareness and concern, along with ascription of responsibility, explained a considerable amount of variance in personal norm (in line with our second (H1.2) and fourth (H1.4) hypotheses). Interestingly, these two belief constructs (i.e., awareness and concern) are indeed related (supported by the principal component analysis). Additionally, the VBN constructs (awareness and concern, ascription of responsibility) as conceptualized and measured in this study are better predictors of personal norm (an attitudinal construct) than increasingly specific beliefs (e.g., a causal relationship of ecological awareness and environmental concern predicting personal ascription of responsibility). This suggests that, in the case of OIT hobbyists, awareness and concern have a direct effect on personal norms and the construct is not just mediated by ascription of responsibility. These findings confirm Nordlund and Garvill's (2002) study on pro-environmental behavioral intention (i.e., recycling behavior and energy conservation) where ecological problem awareness was first found to have a direct effect on personal norms. Further, these findings suggest that future educational outreach campaigns will likely activate greater moral obligation by including messages to promote awareness and concern, not just ascription of responsibility.

Our third (H1.3) and fifth (H1.5) hypotheses were confirmed, as awareness and concern and ascription of responsibility had positive, direct effects on intention to make both future purchase and disposal decisions with preventing the spread of AIS in mind. Other studies have also found that environmental concern (Mehmetoglu, 2010) and awareness of ecological issues (Cottrell, 2003) have direct effects on responsible environmental behavioral intention, indicating that increasing awareness of AIS (through various campaign outlets), fostering concern for the environment by demonstrating negative ecological impacts of AIS, and personalizing OIT hobbyists' responsibility to prevent the spread of AIS may yield greater adoption of recommended behaviors.

In regard to our sixth (H1.6) hypothesis, personal norms was the only significant predictor of future purchase decisions and was associated with a greater standardized coefficient than perceived behavioral control for future disposal decisions. Previous studies have indicated that personal norms may play a larger role than other constructs in explaining behavioral intention (Minton \& Rose, 
1997), indicating that fostering a moral obligation to perform desired behaviors may be an effective campaign strategy to elicit behavior change. Further, our findings confirm that intentions to perform different behaviors are influenced by different theoretical constructs (Stern, 2000); thus, OIT outreach strategies may be more effective if they address purchase and disposal behaviors separately.

Our seventh (H2.1) hypothesis was not supported. The fact that the subjective norm construct did not significantly predict OIT hobbyists' purchase intentions (and was associated with a relatively low standardized coefficient for disposal intentions) calls for future research. Given that there are OIT hobbyist forums and clubs, some of which are species specific, would suggest that subjective norms could play a substantial role in behavioral intentions. It is important to note that our findings may be related to poor questionnaire item construction, as only two measures were retained during the principle component analysis and the factor was associated with a low eigenvalue. Although we retained the subjective norm construct to fully test our integrated model, more robust measures of subjective norms are needed to determine the true influence among OIT hobbyists' purchase and disposal behaviors.

The fully integrated model (i.e., awareness and concern, ascription of responsibility, and personal norm from VBN, and subjective norm and perceived behavioral control from TPB) significantly predicted both intentions to make future purchase and disposal decisions with preventing the spread of AIS in mind. However, only constructs from VBN were significant in explaining future purchase decisions and explained more variance in future disposal decisions than significant TPB constructs. While the literature does not explore differences in the explanatory power of the two theoretical models, as represented in this study, previous research has shown that adding personal norms to a model of the TPB decreases the variance explained by the TPB constructs (Harland et al., 1999). In our study, subjective norm was not significant in either model and perceived behavioral control was not significant in predicting purchase behaviors (i.e., H2.2 was not supported in regard to purchase behaviors, but was supported in regard to disposal behaviors) when awareness and concern and ascription of responsibility were introduced. These results (not taking into consideration the possibility of design issues with the subjective norm construct discussed above) suggest that OIT hobbyists' behaviors are best explained by internalized feelings (and to a lesser extent perceived ability) than by social pressure, confirming previous research that found behavior-specific knowledge and personal norms have greater influence over private-sphere behaviors, such as "green consumerism" and environmentally friendly waste disposal, than public-sphere behaviors (Stern, 2000). 
It is interesting to note that perceived behavioral control's significant effect on future disposal decisions but not future purchase decisions is opposite to van Birgelen et al.'s (2008) findings on "green" purchase and disposal decisions relating to beverages. These authors suggest that perceived control is likely lowest (i.e., highest burden on individuals) with "green" beverage container disposal decisions because of the effort required (e.g., driving to a waste management location to recycle beverage containers). In the case of OIT hobbyists, the burden (i.e., lowest perceived control) may be experienced during the purchasing process due to the presence of aquatic "hitchhikers" (Keller \& Lodge, 2007) that attach to desired species, or the sale of mislabeled species (Maki \& Galatowitsch, 2004).

The SUR analyses resulted in the failure to prove our tenth hypothesis (H3.0); significant differences existed between the effect of theoretical constructs on purchase and disposal intentions. Specifically, personal norm and ascription of reasonability had a greater effect on future purchase decisions, while awareness and concern, as well as perceived behavioral control, had a greater effect on future disposal decisions. This finding confirms an early study of energy conservation in which Midden and Ritsema (1983) suggested that behaviors need to be clearly defined and cannot be treated as homogenous because the influence of constructs will differ based on the desired behavior. This finding has important practical implications for developing future OIT hobbyist education campaigns. Specifically, different outreach messages should be developed to target purchase and disposal behaviors independently, as shorter messages are more effective at reaching audiences engaging in leisure behavior (Ham, 2013). Therefore, future education campaigns aimed at OIT hobbyists should:

a. focus on attributing responsibility for AIS spread to hobbyists and fostering personal obligations to stop AIS spread when targeting aquatic species purchasing decisions; for example, campaign messages should focus on hobbyists' responsibility to purchase from reputable retailers that accurately identify species and avoid purchasing species that are not legal in their region (Maki \& Galatowitsch, 2004); and

b. appeal to a personal expectation to protect the environment from AIS by emphasizing that they (the hobbyist) are in charge of their own purchasing decisions.

When targeting future disposal decisions, campaign strategies should reduce perceived effort of disposal practices and focus on environmental consequences of invasive species establishment and spread. For instance, campaign messages could provide examples of the negative impacts of AIS (i.e., loss of biodiversity and impacts on recreation; ANS Task Force, 2012) that can result when hobbyists release their aquatic species into the environment. Additionally, while awareness 
and concern are related to more altruistic value orientations (and those with biospheric value orientations may share similar moral obligations), Schultz and Zelezny (2003) suggest that reframing environmental messages to appeal to those with more egoistic value orientations (e.g., self-enhancing values) can increase the effectiveness of educational messages aiming to change behavior. For example, future campaigns targeting disposal decisions can enhance awareness and concern for AIS by informing hobbyists about instances of AIS "taking over" their outdoor pond or water garden and outcompeting their other aquatic species.

\section{Study limitations}

A few study limitations exist, which should be taken into consideration when interpreting the study findings. The results may not be representative of all OIT hobbyists, particularly those who are novice hobbyists, because the sample population was OIT hobbyist event attendees. Hobbyists who attend trade shows, auctions, and expos may be more specialized and more likely to make a personal effort to engage in activities to sustain their hobby. A study by McFarlane and Boxall (1996) found that more-experienced birders were more willing than less-experienced birders to engage in conservation behaviors, suggesting that any future studies of OIT hobbyists should include an array of hobbyist levels. Nevertheless, given the high response rate $(83 \%)$ and absence of nonresponse bias, our results are generalizable to hobbyists who attend OIT events in the Great Lakes region.

\section{Conclusions}

This study's findings have both theoretical and managerial implications. Theoretically, we found that VBN constructs were better predictors of intention to perform OIT purchase and disposal behaviors with AIS prevention in mind than TPB constructs. This finding is strengthened when all VBN constructs were modeled to have direct, positive effects on behavioral intentions. That is, the belief constructs theorized in our model (i.e., ecological problem awareness, environmental concern, and ascription of responsibility), which are traditionally viewed as causal predictors of behavioral intention in VBN, directly predicted behavioral intention. Furthermore, the inclusion of those belief constructs enhanced the explanatory power of the integrated model, despite the fact that they reduced or eliminated the effects of TPB constructs (i.e., perceived behavioral control and subjective norms, respectively). Additionally, our study suggests that future research should explicitly include environmental concern questionnaire items within the awareness of consequences construct. 
Related to environmental management, this study's findings suggest strategies to reduce the release of AIS by OIT hobbyists through effective educational outreach campaigns. To increase campaign effectiveness, this study identified that activating moral obligations and ascription of responsibility to OIT hobbyists may increase the likelihood that they will make purchase decisions with AIS prevention in mind. Additionally, this study identified that increasing AIS awareness and general environmental concern, as well as reducing perceived burdens, may increase the likelihood that OIT hobbyists make disposal decisions with AIS prevention in mind. Understanding differences in the unique effects of theoretical constructs on separate behaviors (i.e., making future purchase and future disposal decisions with preventing the spread of AIS in mind) may improve the success of potential campaigns by focusing on constructs that are most relevant to OIT hobbyists when performing specific types of behaviors. If successful, OIT hobbyists may no longer be a vector of AIS spread and, thus, biodiversity may be less threatened, environmental managers may be able to reduce their AIS mitigation efforts, recreational water users (particularly anglers) may not lose recreational access and valued sports fisheries, and the public may experience a decline in the absorbed cost of infrastructure damage caused by AIS.

\section{Acknowledgments}

This project was conducted in collaboration with Illinois-Indiana Sea Grant. Project funding was provided by the United States Environmental Protection Agency's Great Lakes Restoration Initiative and the Illinois Department of Natural Resources from a U.S. Fish \& Wildlife Service award.

\section{Appendix A}

\section{Questionnaire items removed during principal component analysis (factor loadings < .60)}

a Measured on a 5-point Likert-type scale from not at all aware to extremely aware.

${ }^{b}$ Measured on a 5-point Likert-type scale from not at all concerned to extremely concerned.

c Measured on a 5-point Likert-type scale from strongly disagree to strongly agree.
} 


\section{References}

Abrahamse, W., \& Steg, L. (2011). Factors related to household energy use and intention to reduce it: The role of psychological and socio-demographic variables. Human Ecology Review, 18(1), 30-40.

Acuña, E., \& Rodriguez, C. (2004). The treatment of missing values and its effect in the classifier accuracy. In D. Banks, F. R. McMorris, P. Arabie, \& W. Gaul (Eds.), Classification, clustering, and data mining applications (pp. 639-647). Berlin, NY: Springer.

Ajzen, I. (1991). The theory of planned behavior. Organizational Behavior and Human Decision Processes, 50, 179-211.

Ajzen, I. (2002). Perceived behavioral control, self-efficacy, locus of control, and the theory of planned behavior. Journal of Applied Social Psychology, 32(4), 665-683.

ANS Task Force (Aquatic Nuisance Species Task Force). (2012). What are ANS? Retrieved from www.anstaskforce.gov/ans.php

Bamberg, S., \& Schmidt, P. (2003). Incentives, morality, or habit?: Predicting students' car use for university routes with the models of Ajzen, Schwartz, and Triandis. Environment and Behavior, 35(2), 264-285.

Black, J. S., Stern, P. C., \& Elworth, J. T. (1985). Personal and contextual influences on household energy adaptations. Journal of Applied Social Psychology, 70(1), 3-21.

Bremner, A., \& Park, K. (2007). Public attitudes to the management of invasive non-native species in Scotland. Biological Conservation, 139(3-4), 306-314.

Burt, J. W., Muir, A., Piovia-Scott, J., Veblen, K. E., Chang, A. L., Grossman, J. D., \& Weiskel, H. W. (2007). Preventing horticultural introductions of invasive plants: Potential efficacy of voluntary initiatives. Biological Invasions, 9, 909-923.

Cheung, S. F., Chan, D. K.-S., \& Wong, Z. S.-Y. (1999). Reexamining the theory of planned behavior in understanding wastepaper recycling. Environment and Behavior, 31, 587-612.

Chu, P., \& Chiu, J. (2003). Factors influencing household waste recycling behavior: Test of an integrated model. Journal of Applied Social Psychology, 33(3), 604-626. 
Corraliza, J. A., \& Berenguer, J. (2000). Environmental values, beliefs, and actions: A situational approach. Environment and Behavior, 32(6), 832-848.

Cottrell, S. P. (2003). Influence of sociodemographics and environmental attitudes on general responsible environmental behavior among recreational boaters. Environment and Behavior, 35, 347-375.

Cucherousset, J., \& Olden, J. D. (2011). Ecological impacts of non-native freshwater fishes. Fisheries, 36(5), 215-230.

Dillman, D. A. (2007). Mail and Internet surveys: The tailored design method (2nd ed., 2007 update). Hoboken, NJ: John Wiley \& Sons.

Duggan, I. C. (2010). The freshwater aquarium trade as a vector for incidental invertebrate fauna. Biological Invasions, 12, 3757-3770.

Fuller, P. L. (2003). Freshwater aquatic vertebrate introductions in the United States: Patterns and pathways. In G. M. Ruiz \& J. T. Carlton (Eds.), Invasive species: Vectors and management strategies (pp. 123-151). Washington, DC: Island Press.

Gozlan, R. E. (2008). Introduction of non-native freshwater fish: Is it all bad? Fish and Fisheries, 9(1), 106-115.

Green, A., \& Armson, R. (2005). A survey about aquarium, outdoor pond, and water garden issues: Results and technical report (Technical Report \#05-02). Minnesota Center for Survey Research.

Guagnano, G. A., Stern, P. C., \& Dietz, T. (1995). Influences on attitude-behavior relationships: A natural experiment with curbside recycling. Environment and Behavior, 27(5), 699-718.

Ham, S. H. (2013). Interpretation: Making a difference on purpose. Golden, CO: Fulcrum Publishing.

Harland, P., Staats, H., \& Wilke, H. A. M. (1999). Explaining proenvironmental intention and behavior by personal norms and the theory of planned behavior. Journal of Applied Social Psychology, 29(12), 2505-2528.

Hermoso, V., \& Clavero, M. (2013). Revisiting ecological integrity 30 years later: Non-native species and the misdiagnosis of freshwater ecosystems. Fish and Fisheries, 14(3), 416-423.

Hull, R. B. (2006). Infinite nature. Chicago, IL: University of Chicago Press. 
Johnston, M. J., \& Marks, C. A. (1997). Attitudinal survey on vertebrate pest management in Victoria. Frankston, Australia: Government of Victoria Department of Natural Resources and the Environment.

Kaiser, F. G., Hubner, G., \& Bogner, F. X. (2005). Contrasting the theory of planned behavior with the value-belief-norm model in explaining conservation behavior. Journal of Applied Social Psychology, 35(10), 2150-2170.

Kareiva, P., Watts, S., McDonald, R., \& Boucher, T. (2007). Domesticated nature: Shaping landscapes and ecosystems for human welfare. Science, 316, 1866-1869.

Keller, R. P., \& Lodge, D. M. (2007). Species invasions from commerce in live aquatic organisms: Problems and possible solutions. American Institute of Biological Sciences, 57(5), 428-436.

Maki, K., \& Galatowitsch, S. (2004). Movement of invasive aquatic plants into Minnesota (USA) through horticultural trade. Biological Conservation, $118,389-396$.

Mayer, J., \& Seekamp, E. (2013). Addressing aquatic invasive species in Illinois: Focus groups and interviews with organisms-in-trade participants. Raleigh, NC: North Carolina State University.

McFarlane, B. L., \& Boxall, P. C. (1996). Participation in wildlife conservation by birdwatchers. Human Dimensions of Wildlife, 1(3), 1-14.

Mehmetoglu, M. (2010). Factors influencing the willingness to behave environmentally friendly at home and holiday settings. Scandinavian Journal of Hospitality, 10(4), 430-447.

Midden, C. J. H., \& Ritsema, B. S. M. (1983). The meaning of normative processes for energy conservation. Journal of Economic Psychology, 4, 37-55.

Mills, E. L., Leach, J. H., Carlton, J. T., \& Secor, C. L. (1994). Exotic species and the integrity of the Great Lakes. BioScience, 44(10), 666-676.

Minton, A. P., \& Rose, R. L. (1997). The effects of environmental concern on environmentally friendly consumer behavior: An exploratory study. Journal of Business Research, 40, 37-48.

National Research Council, 2008. Great Lakes shipping, trade, and aquatic invasive species (Special Report 291). Washington, DC: Transportation Research Board. 
NOAA (National Oceanic and Atmospheric Administration). (2015). Great Lakes Restoration Initiative, Invasive Species. Retrieved from www.regions. noaa.gov/great-lakes/index.php/great_lakes-restoration-initiative/invasivespecies/

Nordlund, A. M., \& Garvill, J. (2002). Value structures behind proenvironmental behavior. Environment and Behavior, 34, 740-756.

Nordlund, A. M., \& Garvill, J. (2003). Effects of values, problem awareness, and personal norm on willingness to reduce personal car use. Journal of Environmental Psychology, 23(4), 339-347.

Padilla, D. K., \& Williams, S. L. (2004). Beyond ballast water: Aquarium and ornamental trades as sources of invasive species in aquatic ecosystems. Frontiers in Ecology and the Environment, 2(3), 131-138.

Rixon, C. A. M., Duggan, I. C., Bergeron, N. M. N., Ricciardi, A., \& Macisaac, H. J. (2005). Invasion risks posed by the aquarium trade and live fish markets on the Laurentian Great Lakes. Biodiversity and Conservation, 14, 1365-1381.

Rosaen, A. L., Grover, E. A., \& Spencer, C. W. (2012). The costs of aquatic invasive species to Great Lakes states. East Lansing, MI: Anderson Economic Group.

Rothlisberger, J. D. (2009). Human-mediated dispersal of aquatic nonindigenous species: Impacts and interventions (Doctoral dissertation, University of Notre Dame). Retrieved from http://etd.nd.edu/ETD-db/theses/available/etd08302009-164109/unrestricted/RothlisbergerJ082009.pdf

Ruiz, G. M., \& Carlton, J. T. (2003). Invasion vectors: A conceptual framework for management. In G. M. Ruiz \& J. T Carlton (Eds.), Invasive species: Vectors and management strategies (pp. 459-504). Washington, DC: Island Press.

Sahin, E. (2013). Predictors of Turkish elementary teacher candidates' energy conservation behaviors: An approach on value-belief-norm theory. International Journal of Environmental and Science Education, 8(2), 269-283.

Schultz, P. W., \& Zelezny, L. (2003). Reframing environmental messages to be congruent with American values. Human Ecology Review, 10(2), 126-136.

Schwartz, S. H. (1968). Words, deeds, and the perception of consequences and responsibility in action situations. Journal of Personality and Social Psychology, 10(3), 232-242.

Schwartz, S. H. (1977). Normative influences on altruism. In L. Berkowitz (Ed.), Advances in experimental social psychology (Vol. 10, pp. 221-279). New York, NY: Academic Press. 
Selge, S., Fischer, A., \& van der Wal, R. (2011). Public and professional views on invasive non-native species: A qualitative social scientific investigation. Biological Conservation, 144, 3089-3097.

Sharp, R. L., Larson, L. R., \& Green, G. T. (2011). Factors influencing public preferences for invasive alien species management. Biological Conservation, 144, 2097-2104.

Steg, L., Dreijerink, L., \& Abrahamse, W. (2005). Factors influencing the acceptability of energy policies: A test of VBN theory. Journal of Environmental Psychology, 25(4), 415-425.

Steg, L., \& Vlek, C. (2009). Encouraging pro-environmental behaviour: An integrative review and research agenda. Journal of Environmental Psychology, $29,309-317$.

Stern, P. C. (2000). Toward a coherent theory of environmentally significant behavior. Journal of Social Issues, 56(3), 407-424.

Stern, P. C, Dietz, T., Abel, T., Guagnano, G. A., \& Kalof, L. (1999). A value-beliefnorm theory of support for social movements: The case of environmentalism. Human Ecology Review, 6(2), 81-97.

Stern, P. C., Dietz, T., \& Kalof, L. (1993). Value orientations, gender, and environmental concern. Environment and Behavior, 25(5), 322-348.

Stiers, I., Crohain, N., Josens, G., \& Triest, L. (2011). Impact of three aquatic invasive species on native plants and macroinvertebrates in temperate ponds. Biological Invasions, 13, 2715-2726.

van Birgelen, M., Semeijn, J., \& Keicher, M. (2008). Packaging and proenvironmental consumption behavior: Investigating purchase and disposal decisions for beverages. Environment and Behavior, 41(1), 125-146.

Vander Zanden, M. J., \& Olden, J. D. (2008). A management framework for preventing the secondary spread of aquatic invasive species. Canadian Journal of Fisheries and Aquatic Sciences, 65(7), 1512-1522.

Zellner, A. (1962). An efficient method of estimating seemingly unrelated regressions and tests for aggregation bias. Journal of the American Statistical Association, 57(289), 348-368. 
This text is taken from Human Ecology Review, Volume 21, Number 2, 2015, published 2015 by ANU Press, The Australian National University, Canberra, Australia. 